1Universidade Federal do Espírito Santo (Ufes) Vitória (ES), Brasil. amandasulti@gmail.com

2 Universidade Federal do Espírito Santo (Ufes), Departamento de

Enfermagem, Programa de Pós-Graduação em Saúde Coletiva - Vitória (ES), Brasil.

ritacdl@uol.com.br

3 Universidade Federal do Espírito Santo (Ufes), Programa de PósGraduação em Saúde

Coletiva - Vitória (ES), Brasil.

paulinhassf_enf@yahoo. com.br

4 Universidade Federal do Espírito Santo (Ufes) -

Vitória (ES), Brasil. cnfelsky@gmail.com

5 Universidade Federal do Espírito Santo (Ufes) -

Vitória (ES), Brasil.

heleticiagalavote@yahoo.

com.br

\section{O discurso dos gestores da Estratégia Saúde da Família sobre a tomada de decisão na gestão em saúde: desafio para o Sistema Unico de Saúde}

\author{
The manager's speech of the Family Health Strategy on decision \\ making in healthcare management: a challenge for the Unified \\ Health System
}

Amanda Del Caro Sulti1; Rita de Cássia Duarte Lima²; Paula de Souza Silva Freitas³; Camila Nogueira Felsky4; Heletícia Scabelo Galavote ${ }^{\mathbf{4}}$

RESUMO O artigo discute a tomada de decisão na gestão municipal a partir dos discursos dos gestores da Estratégia Saúde da Família (ESF). Trata-se de uma pesquisa com abordagem qualitativa, realizada por meio de observação direta de uma equipe de saúde e entrevistas. Dessa forma, apreendeu-se que os gestores da ESF assumem-se como o centro da equipe, predominando a hierarquização das relações e tomadas de decisão centradas na gestão. Assim, é necessário compreender as estruturas de poder no interior das instituições de saúde, já que são as relações do cotidiano que determinam o caminhar da gestão. É preciso que esses espaços ampliem os momentos de escuta dos trabalhadores no processo de gestão compartilhada.

PALAVRAS-CHAVE Atenção Primária à Saúde; Estratégia Saúde da Família; Gestão em saúde; Política de saúde.

ABSTRACT The article discusses the decision making in the municipal management from the managers speeches of the Family Health Strategy (ESF). It is about a research with qualitative approach, carried out by means of direct observation of a health team and interviews. Therefore, it was impounded that the ESF managers are assumed as the center of the team, prevailing the ranking of relationships and decision makings centered on management. Thus, it is necessary to understand the power structures within health institutions, once are the daily relationships that determine the management progress. It is needed that those spaces enlarge the listening moments for workers in the shared management process.

KEYWORDS Primary Health Care; Family Health Strategy; Health management; Health policy. 


\section{Introdução}

A partir da promulgação da Constituição Federal de 1988, a saúde passou a ser direito do cidadão e dever do Estado. O texto constitucional, nos artigos 196 a 200, incorporou princípios da reforma sanitária brasileira e determinou uma nova lógica organizacional ao criar o Sistema Único de Saúde (SUS). Dessa forma, para operacionalizá-lo, a gestão dos serviços passou a se organizar de forma descentralizada, com comando único em cada esfera de governo, trazendo para os municípios o papel de protagonista da gestão do sistema de saúde em seu território e a responsabilidade pela Atenção Básica (AB), assumindo, a partir desse momento, as ações e os serviços de saúde (SOLLA, 2010).

Nesse cenário, o advento da reforma sanitária e a construção do SUS criaram novas demandas assistenciais, gerenciais e intersetoriais, induzindo à necessidade de mudança na forma de governar. Assim, a gestão dos serviços de saúde assume significado estratégico para a consolidação das políticas do SUS e para a reorganização dos processos de trabalho dos profissionais da saúde, para o atendimento das necessidades da população (FERREIRA, 2012).

No entanto, observa-se que os espaços dos serviços de saúde são palcos de ação de diversos atores sociais que possuem intencionalidades na maneira de organizar seu processo de trabalho. Os profissionais de saúde atuam fazendo uma mescla de seus territórios privados de ação e o processo público de trabalho, caracterizando, dessa forma, o cotidiano desses serviços: normas e papéis institucionais contra práticas privadas de cada trabalhador (MERHY, 2007).

Nesse sentido, falar em gestão em saúde, na perspectiva das relações e do trabalho vivo em ato - aquele em que, no mesmo momento em que o trabalho é executado, o produto é realizado - é considerar o processo de subjetividade, ou seja, a forma como cada trabalhador opera o seu trabalho no dia a dia dos serviçOS (CECILIO; MENDES, 2004), visto que, no cotidiano dos serviços de saúde, apesar da adoção de práticas centradas em atos prescritivos, burocráticos e com alto consumo de procedimentos, o trabalho em saúde permite que o trabalhador opere com certo grau de liberdade e autonomia (MERHY, 2002). Por meio desse espaço de liberdade, os trabalhadores são capazes de atualizar antigos modelos e produzir novos, assim como o fazem a comunidade e os usuários, de forma que são as escolhas do conjunto desses atores que convertem as normas e os desenhos institucionais em atos e práticas concretas e produzem a realidade social. Ou seja, mesmo o SUS sendo organizado a partir de normas, protocolos e programas, são os sujeitos inseridos nele que conformam, de fato, o desenho institucional e seus fluxos.

Esse é um grande desafio à gestão, já que a intervenção em saúde depende da construção das relações, da configuração das redes cooperativas, que não podem ser respondidas com a normalização do processo de trabalho. Além disso, o não reconhecimento de que toda gestão é resultado de uma interação entre indivíduos tende a reproduzir "formas burocratizadas de trabalho, com empobrecimento subjetivo e social dos trabalhadores e dos usuários" (CAMPOS, 2003, P. 86).

Assim, parte-se da lógica de que o trabalho em saúde se realiza a partir do encontro entre trabalhadores e usuários, formando uma rede de relações a partir da qual os produtos referentes ao cuidado ganham materialidade. No seu dia a dia, o trabalhador faz uso de diversas tecnologias, saberes e instrumentos e tem como objeto de ação o homem enquanto sujeito social. A gestão constrói-se em uma relação e não pode ser limitada à divisão entre os que produzem e os que consomem, pois a produção e o consumo são simultâneos e acontecem do encontro entre o trabalhador e o usuário (MERHY, 2007).

Tendo por objeto o trabalho humano, que, disposto sob o tempo e guiado por finalidades, deveria realizar tanto a missão das 
organizações como o interesse dos trabalhadores (BRASIL, 2009), esse trabalho entende a gestão em saúde como um campo de ação humana que visa à coordenação, articulação e interação de recursos e trabalho humano para a obtenção de fins, metas e objetivos, que tem como princípios governar os processos políticos implicados com a formulação e a decisão sobre os caminhos a serem adotados e os processos de produção de atos de saúde (MERHY, 2002). Mais ainda, entende-se a gestão como um processo em construção, que se faz no cotidiano do trabalho e que possui, através do agir, potencial transformador para a construção de um modelo assistencial que trabalhe para a consolidação do SUS (VANDERLEI, 2005).

A gestão engloba os processos políticos implicados com a formulação e a decisão sobre os caminhos a serem tomados, assim como os processos de produção de atos de saúde. Merhy ainda afirma que, para governar em saúde, os gestores precisam de uma caixa de ferramentas contendo "tecnologias que permitam a sua ação nos terrenos da política, das práticas institucionais e dos processos de trabalho" (MERHY, 2002, P. 157). Faz uso de tecnologias leve-duras, como as normatizações burocráticas e técnicas, e, também, de tecnologias leves, ou das relações, sendo fundamental para a orientação dos processos de trabalho (MERHY, 2002).

Nesse contexto, os gestores apresentam-se como peças fundamentais para a construção de modelos de gestão que sejam capazes de, além de contribuir para a produção de saúde, contribuir para a constituição de sujeitos que tenham seus projetos pessoais articulados com a responsabilização na construção de um modelo de atenção que cumpra os princípios do SUS. Isso se afirma tendo em vista que municípios que investiram em reformas na estrutura dos sistemas locais de saúde, mas que não alteraram a forma de como se faz a gestão dos serviços, não conseguiram alcançar novas produções de saúde (PIMENTA, 2006).
Assim posto, é importante observar que

[...] a gestão não é apenas a organização do processo de trabalho, mas é o que se passa entre vetores-dobras que o constituem. Os vetores, entretanto, não estabelecem entre si relações deterministas ou determinadas, mas relações de intercessão, sustentadas num princípio de inseparabilidade e co-extensão, de tal modo que tais vetores configuram-se bem mais como dobras de um plano de produção. (BARROS; BENEVIDES DE BARROS, 2007, P. 62).

Pela gestão, perpassam, também, questões referentes aos desejos, necessidades, interesses dos sujeitos envolvidos, saberes inseridos nos processos de trabalho, poder, modo de operar as relações e a coletivização das políticas públicas. Assim, o cenário da gestão em saúde é complexo e inserido na intercessão entre os processos de trabalho, os sujeitos e o poder (BARROS; BENEVIDES DE BARROS, 2007).

Este artigo tem como objetivo analisar o processo de tomada de decisão na prática da gestão no âmbito da Estratégia Saúde da Família (ESF), a partir dos discursos dos gestores, tendo como alicerce o pressuposto de que a gestão pode ser conceituada não como um lugar, mas, sim, como um "elemento-passagem entre fluxos de trabalhos/saberes; fluxos de subjetivação/sujeito; fluxos de relação/poder" (BARROS; BARROS, 2007, P. 64).

\section{Metodologia}

Para alcançar o objetivo deste estudo, foi necessário buscar os significados dos discursos, assim como levar em consideração as relações que se estabelecem entre os sujeitos inseridos no processo de gestão. Em decorrência disso, o percurso metodológico seguido foi orientado pela abordagem qualitativa. Foram utilizados como instrumentos metodológicos para a coleta de dados: a observação direta de uma equipe de ESF, a construção de um diário de campo e entrevistas 
individuais semiestruturadas com os gestores da ESF de um dos municípios da região metropolitana da Grande Vitória (ES).

Sabe-se que todos os sujeitos que estão inseridos na ESF fazem parte do processo de gestão com suas capacidades de abrir espaços de disputas de projetos e dar sentido ao trabalho em saúde (BRASIL, 2009; MERHY, 2007), de forma que "tanto o usuário governa, quanto os trabalhadores" (MERHY, 2007, P. 24). No entanto, para o alcance dos objetivos deste estudo, foram considerados gestores os profissionais que ocupam uma situação formal na 'máquina estatal', assim, ocupam um lugar que possibilita controle na administração de recursos, poderes instituídos e que são, portanto, capazes de operar recursos para dar sentindo ou não a determinadas políticas públicas (MERHY, 2007). Dessa forma, os participantes do presente estudo foram o secretário municipal de saúde, o coordenador municipal de Atenção Básica, um integrante do Núcleo de Estratégia Saúde da Família e um coordenador de Unidade de Saúde da Família (USF).

Este estudo é uma das dimensões da pesquisa 'Análise das principais modelagens de gestão na Estratégia Saúde da Família no Espírito Santo', desenvolvida pelo Núcleo de Pesquisa em Planejamento, Avaliação e Gestão em Saúde Coletiva (NUPGASC) do Programa de Pós-Graduação em Saúde Coletiva da Universidade Federal do Espírito Santo, a qual foi submetida à apreciação do Comitê de Ética em Pesquisa do Centro de Ciências da Saúde da Universidade Federal do Espírito Santo (CEP/CCS/Ufes) e aprovada em 28 de agosto de 2013 - parecer n. ${ }^{\circ}$ 363.867 .

Foi solicitada ao gestor municipal de saúde uma autorização para a realização da pesquisa no âmbito municipal. $O$ projeto foi aprovado pela Gerência de Desenvolvimento de Recursos Humanos do município e pelo secretário municipal de saúde, por meio da emissão da declaração de anuência de desenvolvimento de pesquisa. Além disso, cada participante do estudo foi devidamente esclarecido sobre a pesquisa e manifestou a anuência da sua participação por meio da assinatura do Termo de Consentimento Livre e Esclarecido.

De forma a manter o sigilo dos participantes, os gestores serão identificados pela letra G (gestor), acompanhada de um numeral arábico: G1 (secretário municipal de saúde), G2 (coordenador da Atenção Básica), G3 (integrante do Núcleo de Estratégia Saúde da Família) e G4 (coordenador de Unidade Saúde da Família).

\section{Resultados e discussão}

Os participantes do presente estudo estão inseridos em uma parcela do organograma da Secretaria Municipal de Saúde. Trata-se, entre outras estruturas, da porção em que está a figura do Secretário Municipal de Saúde, seguido pela Superintendência de Atenção à Saúde. Inserida nessa superintendência está a Gerência de Atenção Primária; abaixo dela, a Gerência de Unidade de Atenção Primária. O Núcleo de Estratégia Saúde da Família não aparece no organograma, contudo, está ligado à Gerência de Atenção Primária.

O processo de trabalho dos profissionais inseridos nessa estrutura é organizado de acordo com essa lógica, de forma que as Equipes de Saúde da Família (EqSF) são acompanhadas de perto pelo Núcleo de Estratégia Saúde da Família, que, por sua vez, possui o papel de dar suporte e monitorar as equipes. Nessa organização, o processo de trabalho do núcleo, de acordo com os discursos dos gestores, é baseado na realização de monitoramento de indicadores in loco, orientações quanto à produção de relatório mensal, além de ser responsável por levar até as equipes as demandas da Secretaria e fazer o caminho contrário.

Então, a minha presença lá não é cobrança intensa. Eu trabalho de acordo que eu vejo a 
situação. Se for uma equipe completa, e estão deixando a desejar, eu dou uma 'chamadinha': Como não tem esse conhecimento? Como vocês não estão conseguindo atender às prioridades? Não falta gente, não falta enfermeiro, não falta médico, né? O que está acontecendo que vocês não estão conseguindo atender na íntegra, uma vez que vocês estão numa equipe completa? (G3).

Entretanto, a função do núcleo na equipe é questionada pelo coordenador da unidade, que, mesmo reconhecendo o papel de apoiador do núcleo, deixa claro até onde cada um pode interferir. Naquele espaço, a última palavra é dele:

Por aqui ser estratégia, antes tinha muito o núcleo como o 'detentor' da unidade, mas, quando eu vim pra cá, eu já coloquei que isso não é legal, porque a unidade, o núcleo é um apoiador, mas existe uma gerência, uma superintendência, então, isso tem que ser levado em conta, né? O núcleo é um apoiador? Então, ele vai vir apoiar a unidade, vai vir apoiar o servidor, vai vir trazer alguma novidade, mas ele não é o detentor do poder de gerenciamento dentro da unidade. $\mathrm{Ou}$ como o gerente da unidade, acima do gerente, assim, ele não é. (G4).

Por outro lado, a função da coordenação é discutida em reunião do integrante do núcleo com a equipe da unidade. Durante a observação, pode-se acompanhar o papel do integrante do núcleo na equipe. A reunião foi para orientar a equipe quanto à avaliação externa do Programa de Melhoria do Acesso e da Qualidade (PMAQ) e discutir possíveis melhorias. Além dos indicadores, foram levantadas pelos profissionais questões referentes à organização da unidade (prontuários, padronizações, mudanças na realização das marcações de consultas e exames). Frente a essa demanda, o G4 sugere que essa pauta seja levada para o coordenador da unidade, pois é quem tem capacidade de fazer alterações:
[...] O último tópico trabalhado na reunião foi sobre as dificuldades em terem informações sobre o que ocorre na unidade, visto que ninguém possui acesso ao e-mail da unidade e muitas vezes não são informados das reuniões e capacitações feitas pelo município. Uma das médicas da unidade de saúde ainda afirma que tem dificuldade de sair para capacitações pela resistência da coordenação. Os agentes comunitários de saúde falam que não conseguem ir às assembleias da categoria. (Diário de Campo, 2013).

Além disso, o gestor na unidade de saúde detém o controle sobre instrumentos que impõem sua presença, mesmo quando está fisicamente distante, como o controle sobre a chave da sala da administração, o celular da unidade e a senha do e-mail da unidade de saúde, para onde são enviadas todas as informações e os comunicados. Quando não está na unidade, o coordenador elege um membro de confiança para ser responsável por esses instrumentos administrativos.

Nesse contexto, a dimensão de poder expressa na organização da saúde é designada por controle e disciplinamento. Ela atravessa o cotidiano e é clara no organograma formal da Secretaria. Observa-se, também, que o poder gerencial está 'diluído' entre os gestores, os quais possuem o ensejo de decidir sobre a organização do processo de trabalho dos profissionais. Na pesquisa, podem-se identificar vários mecanismos de uso do poder disciplinar arraigados na gestão da ESF: o controle da equipe no cumprimento de metas - assim como a 'chamadinha' que o G3 direciona às equipes que estão completas, mas que não cumprem seus indicadores - e a centralização dos instrumentos de comunicação nas mãos do coordenador da USF, fazendo com que ele decida sobre a organização das ações da equipe.

Outro ponto importante é que, no cenário da gestão municipal de saúde, observa-se que a figura do secretário é representada, no dia a dia das unidades, principalmente, pelo colegiado gestor. 
De acordo com o secretário municipal de saúde, o apoio institucional e o colegiado gestor foram instituídos para trabalhar com as equipes. Essas duas estruturas têm capacidade de intervir no cotidiano do trabalho e são responsáveis, também, por indicar as propostas que são definidas dentro da secretaria. Apesar desse objetivo, o secretário ressalva que a gestão não faz interferência no dia a dia do processo de trabalho do coordenador. "Eu não sou de interferir cotidianamente lá na unidade. Eu acho que se tem um gestor naquela unidade, ele precisa fazer isso. Ou então ele não pode ser gestor naquela unidade”. (G1).

A gente instituiu o apoio institucional, que é o acompanhamento de um assessor da Política Nacional de Humanização. Ele está trabalhando aqui conosco de março pra abril, e em cada unidade, cada serviço, nós temos um conjunto de apoiadores. Esses apoiadores têm um espaço de encontro aqui para que eles também compreendam seu papel e, a partir disso, façam intervenção nas unidades. [...] Mas ele também leva pensamentos daqui, programas da secretaria, diretrizes, prioridades. Então, se vamos pensar num modelo de acolhimento para as unidades, construímos a proposta, e esses apoiadores vão à unidade e, junto com o colegiado gestor, vão discutir esse novo modelo de acolhimento. (G1).

O colegiado gestor é uma estrutura que foi posta em prática na gestão de G1 e acatada por todas as EqSF do município. Teve início com as capacitações dos gestores locais, para, posteriormente, ser implantada nas unidades. Interessante observar que essa é uma proposta que as equipes, obrigatoriamente, devem implementar.

Ela fez a formação com os gestores locais primeiro, e, aí, nós trouxemos a proposta pra unidade. Montamos um conselho, fizemos a eleição dos conselheiros, como deveria ser, e começamos as reuniões. (G4).
Através das falas dos gestores, uma dupla de apoiadores marca reuniões nas unidades de saúde, uma vez ao mês, para levar as demandas da secretaria e também escutar os profissionais. A composição dos profissionais é de escolha das próprias equipes das unidades, por meio de votação entre os membros, objetivando ter um representante de cada categoria profissional no colegiado gestor.

Temos o colegiado gestor e o apoio institucional. O colegiado gestor tem vários níveis aqui na secretaria: o colegiado do gabinete, que são as superintendências, as gerências e os secretários, com reunião mensal. [...]; tem um colegiado da vigilância, que se reúne com os gerentes das unidades uma vez por mês também; nós temos um apoiador institucional do Ministério da Saúde, que vem uma vez por mês, e, nesse momento, os gerentes das unidades também participam traçando objetivos. Já o apoio institucional é formado por profissionais daqui da secretaria que trabalham com o colegiado nas unidades. A unidade identifica alguns profissionais. Eles se elegem entre eles: profissionais, o gerente e a secretaria. Então, tudo que vai ser alterado, por exemplo, a agenda, nós fazemos uma proposta aqui, testamos aqui e, depois, levamos para as unidades. Cada apoiador, sempre uma dupla fixa, um da vigilância e um da assistência, leva a proposta, discute e traz sugestões. Tem sempre uma pauta nossa e uma pauta da unidade, entendeu? (G2).

Não obstante essa fala, em observação de uma reunião do colegiado gestor, muitos profissionais não sabiam qual era o seu papel naquele espaço, visto que a reunião é sempre marcada pelos representantes da secretaria, assim como a pauta também é definida por eles. Durante essa reunião, a postura dos profissionais frente ao coordenador e aos representantes era de submissão: apenas estavam lá para ouvir as propostas.

Alguns profissionais entraram na sala ainda perdidos por não saberem onde seria a reunião. 
As falas manifestas pelos profissionais eram: 'eu vim porque é obrigatório', 'não sei o que faremos', 'o coordenador falou que era para todo mundo vir'. Os profissionais ainda tinham dúvida do seu papel no colegiado. Até o coordenador entrar na sala, foram improvisadas cadeiras (três profissionais sentaram na maca dos pacientes), aperta de um lado, aperta de outro, enfim, coube todo mundo no consultório. A conversa era de assuntos variados do dia a dia, nenhuma conversa prévia sobre o que significava o colegiado gestor. Junto com o coordenador da unidade, entraram duas representantes da secretaria. Nesse momento, prevaleceu um silêncio para que o coordenador desse início à reunião. (Diário de Campo, 2013).

A pauta do mês, para todas as reuniões de colegiado das unidades, era a discussão da agenda. Levaram uma proposta de modificação e uma discussão para a equipe, baseada em um artigo científico. Porém, poucos da equipe leram o texto, alegando falta de tempo. Essa questão dificultou a participação dos profissionais na discussão. Em determinado momento da reunião, houve confronto de algumas ideias e resistência para modificar a agenda dos profissionais. Assim, a reunião acabou sem nenhuma definição, apenas com o encaminhamento de continuar o assunto no próximo mês.

O que se observa é que o discurso feito pelos gestores sobre o colegiado gestor é diferente do que foi vivenciado na reunião.

Dentro do colegiado gestor, a gente trabalha com a conversa com o funcionário, ver qual a angústia dele, o que está acontecendo, para a gente tentar trabalhar a valorização. [...] Quando tem parceria, e você se mostra igual a eles, se você precisar de alguma coisa que não é da função deles, eles vão prontamente e não sabem dizer não, porque sabem que, toda vez que precisarem, eles vão ter sua ajuda. Então, isso é importante para a gente trabalhar a melhoria deles e nossa também. (G4).
Quando se fala da tomada de decisão no interior das equipes, o G4 também referencia o colegiado gestor como espaço para tal.

O colegiado gestor vem trazendo as demandas deles, as angústias deles. Isso é uma forma de valorização do pensar, uma forma de valorização da opinião deles [...] a gente tem que acatar esse pensamento deles e refletir: o que a gestão está fazendo pra melhorar? (G4).

Importa ressaltar que, apesar da gestão colegiada ter sido eleita como uma proposta de gestão inovadora, em resposta ao modelo gerencial hegemônico, "a instituição de colegiados de gestão não garante, por si só, a distribuição de poder e o estabelecimento de espaços de decisão" (CECILIO; MENDES, 2004, P. 49). Segundo Cecílio (2010), existe uma grande distância entre as formulações propostas e o que de fato acontece nos colegiados gestores. Assim, há dificuldade por parte dos trabalhadores em reconhecer esse espaço como um local efetivo de participação e decisão (CECILIO; MENDES, 2004).

Existe, ao mesmo tempo, na secretaria do município em estudo, tanto práticas de controle e subordinação quanto práticas de busca de uma gestão compartilhada, gerando, como consequência, uma incoerência interna, que acarreta práticas ineficazes na produção da saúde.

De acordo com Franco e Merhy (2013), os gestores acreditam que ditar normas, seguir protocolos e prescrever o trabalho dos profissionais é suficiente para garantir que o cuidado se realize. Entretanto, "isto apenas forma trabalhadores serializados, que vão repetir velhas práticas" (FRANCO; MERHY, 2013, P. 247). Nesse contexto, o trabalhador é, em geral, equiparado a um insumo para o funcionamento dos serviços de saúde, quando, na verdade, ele é o maior protagonista da produção do cuidado, é sujeito ativo, que opera com seus saberes, é desejante, tem projetos, expectativas e atua no mundo do trabalho e do cuidado com suas caixas de ferramentas adquiridas na formação e, sobretudo, 
na experimentação do mundo do trabalho e da vida. Isso é que vai marcando sua atividade (FRANCO; MERHY, 2013).

O processo de trabalho dos gestores analisados na pesquisa é fortemente marcado pela divisão e compartimentalização. Essa divisão do trabalho reafirma as diferenças de poder, ou seja, os gestores que possuem cargos mais altos decidem e planejam para quem vai executar as ações. Com isso, há claro uso do controle e da disciplina, o que acarreta aprisionamento da vontade e da criatividade da maior parte dos trabalhadores, corroborando o fato dos trabalhadores serem considerados mais um recurso para a instituição (CAMPOS, 2007).

É interessante observar que os próprios gestores seguem uma determinada hierarquia, que dificulta o processo de trabalho. Eles também são controlados e vigiados, de forma que o trabalho segue uma linha de mando posta. A dificuldade em trabalhar de forma burocratizada é reconhecida pelos entrevistados.

Essa hierarquia existente no organograma da secretaria municipal de saúde apresenta-se como um obstáculo para os processos de tomada de decisão. Profissionais do Núcleo de Estratégia Saúde da Família e das USF são os que ficam 'reféns' das aprovações das instâncias superiores.

Passa da secretaria para a atenção primária, depois para o núcleo e depois unidade. Existe uma hierarquia a seguir [...] Nós não temos tomadas de decisão. Já tivemos esse espaço, mas, agora, não temos mais, está bem hierárquico. A gente pode até decidir alguma coisa, mas temos que passar para gerência da atenção primária e para superintendência, e, se a superintendência achar conveniente, passa para o secretário. (G3).

De acordo com Littike (2012), a hierarquia conota a centralização do poder nas mãos dos que estão em posição mais elevada nessa escala e, além disso, pressupõe dependência do comando para a realização das atividades. Na pesquisa, a ausência de um espaço favorável para a tomada de decisão é indicada por um gestor.

Ainda não está do jeito que eu gostaria [...] precisa ter espaço. Por isso, a gente pensa que o gestor local precisa estar empoderado, precisa ter capacidade para compreender a Estratégia Saúde da Família. (G1).

A cobrança e o controle excessivo da gestão, que denotam centralização de poder nas mãos de poucos, também são evidenciados na fala do G2 que reconhece que esse tipo de conduta desestimula os profissionais que estão na 'ponta' dos serviços.

[...] o que eu vejo hoje é uma desestimulação total por conta da nova gestão. Eles não estão dando prioridade para o servidor. É muita crítica, como se os problemas fossem eles [...] é uma das coisas que a gente vem tendo mais dificuldade, porque, bem ou mal, (antes) a unidade andava, a gente tinha aquele 'gás', e a gente tá vendo que as equipes estão desestimuladas, e não é só uma questão salarial mesmo, não, é questão de incentivar. É só cobrança. Cobra sem dar. As unidades, como eu te falei, os recursos humanos, estão muito ruins. Tem o programa Mais Médicos, então, está chovendo médicos. Mas não tem auxiliar de enfermagem, não tem ninguém na recepção, não tem quem digite as coisas, entendeu? Não é o Mais Médicos que faz diferença. O que vai fazer são mais auxiliares de enfermagem, mais nutricionistas, mais outras questões. Se eu tivesse dentro da unidade de saúde uma equipe mais completa, com assistente social nas unidades, psicólogo, nutricionista, as pessoas iam parar de querer só o médico. Eles querem só o médico, principalmente, porque eles conhecem só o médico, e eles só vão ao médico quando estão doentes. (G2).

\section{Considerações finais}

As observações e as entrevistas deram subsídios suficientes para verificar que a gestão, 
neste estudo, está centrada na lógica tradicional, evidenciada pelas ações burocráticas, centralizadoras e hierárquicas, pautando-se em lógicas tayloristas. Nesse cenário, as relações entre os próprios gestores, e destes com as equipes, retratam relações de poder centralizadas e formas de controle que superam a valorização da autonomia dos profissionais de saúde. Importante frisar que a concepção dos gestores sobre o processo de gestão é clássica, a qual, em sua maioria, acarreta a adoção de um modelo de gestão pautado no controle e na vigilância.

Observa-se que, quando as atividades voltadas para a tomada de decisão são centradas no papel do gestor formal, na instituição de saúde, tem-se um estilo de governar tradicional, ainda pautado na racionalidade gerencial hegemônica, caracterizado pelo controle e disciplina dos trabalhadores e de seus processos de trabalho (VANDERLEl; ALMEIDA, 2007).

Assim, destacamos que há, na maior parte das vezes, exclusão do trabalhador dos processos decisórios, sua alienação, bem como supervalorização das ações de supervisão e controle em detrimento das atividades de planejamento das práticas de saúde. Vale destacar que a consequência disso, nessa realidade, é um modo de fazer gestão pautado no 'apagar incêndio', onde as decisões são tomadas de maneiras emergenciais.

Ademais, as decisões oriundas da secretaria municipal são apresentadas às equipes a partir do colegiado gestor e do apoio institucional. O Núcleo de Estratégia Saúde da Família tem um claro papel de controle no dia a dia das unidades, vez que são responsáveis por levar o que é instituído pela secretaria. Assim, de acordo com Cecílio (1999), 'quem controla tem poder'.

Entendemos que as estruturas desenhadas na secretaria não valorizam a participação dos profissionais nos processos decisórios, e, por isso, os gestores assumem o seu papel como o centro da equipe, ou seja, a única figura com capacidade para definir os caminhos das equipes.
Os profissionais ainda são vistos como um recurso necessário à instituição, sem ser considerados sujeitos com desejos, vontades e projetos próprios.

Sobre essa questão, entende-se que, no cotidiano da gestão, os processos decisórios dentro das instituições de saúde, assim como a capacidade de dar direcionalidade ao processo de trabalho em saúde, configuram-se como uma das instâncias de poder decorrentes desse processo (CECILIO, 1999; VANDERLEl; ALMEIRA, 2007). O papel do gestor é fundamental na conformação das práticas de saúde na administração dos espaços públicos e privados de cada profissional (MERHY, 1997), de forma que se pense sobre "o uso que se quer fazer do poder" (CECILIO, 1999, P. 328).

Além disso, evidenciamos, também, a ausência de autonomia para tomadas de decisão dentro do organograma burocrático da secretaria. As decisões são obrigadas a seguir uma hierarquia fortemente marcada pelas estruturas instituídas. Essa questão se torna um desafio importante no sentido de descentralizar a tomada de decisão, haja vista a necessidade de autonomia para a definição de ações prioritárias no âmbito das ações de saúde de cada população e das necessidades de cada profissional.

$\mathrm{O}$ que encontramos nesta pesquisa foi semelhante ao que Cecilio (1999) descreveu em suas pesquisas:

[...] determinado modo de se pensar a gestão dos serviços de saúde, em particular do hospital, de recorte democrático, descentralizado, com ênfase na autonomia, direção colegiada em todos os níveis da organização é, paradoxalmente, visto como controlista por esses mesmos trabalhadores, para quem se supunha estar garantindo uma maior participação da gestão. (CAMPOS, 1992; CECILIO, 1994 APUD CECILIO, 1999, P. 316).

Uma suposição para esse fato contraditório é a de que as linhas de mando e poder, apesar de não existirem na estrutura do 
colegiado gestor, continuam permeando as relações dos gestores. Além disso, percebe-se que as relações de poder que permeiam o cotidiano desses serviços de saúde são pautadas no controle. Os atos de controle ficaram evidentes em várias falas, como, por exemplo: o discurso rígido direcionado às equipes que não cumprem as metas; o controle no acesso às informações; a presença dos apoiadores nas reuniões, na unidade, com a função de levar até as equipes as 'ideias de dentro da secretaria'; e as linhas de mando verticais que se estabelecem.

Dessa forma, promover mudanças nas formas de gestão implica reorientar as distribuições de poder. Assim, as relações de poder e a polarização entre autonomia e controle se constituem sempre como um espaço de tensão e de potência, ao possibilitar reinventar as relações envolvidas no processo (MERHY, 1997; CECILIO, 1999).

Entretanto, encontramos perspectivas de mudanças nessa forma de conduzir a gestão do município, a partir dessas mesmas iniciativas: colegiado gestor e apoio institucional. Porém, é preciso que esses espaços sejam introjetados pelos profissionais, para que se tornem protagonistas nos processos de produção da gestão e da tomada de decisão.

Entende-se, ainda, que os diversos profissionais, cada um com seus saberes específicos e projetos pessoais, direcionam as ações de saúde cotidianas de acordo com seus interesses e os recortes interessados de dada realidade.

\section{Referências}

BRASIL. Ministério da Saúde. Cartilha da politica nacional de humanização: gestão participativa e co-gestão. Brasília: Ministério da Saúde, 2009.

BARROS, M. E. B.; BENEVIDES DE BARROS, R. Da dor ao prazer no trabalho. In: BARROS, M. E. B.; SANTOS, S. B. (Org.). Trabalhador da saúde: muito prazer - protagonismo dos trabalhadores na gestão do trabalho em saúde. Porto Alegre: Unijuí, 2007. p. 61-72.

CAMPOS, G. W. S. Paidéia e a gestão: indicações metodológicas sobre o apoio. In: . Saúde Paidéia. São

Paulo: Hucitec, 2003. P. 85-102.

Um método para análise e co-gestão de coletivos: a constituição do sujeito, a produção de valor de uso e a democracia em instituições: método da roda. 3. ed. São Paulo: Hucitec, 2007.

CECILIO, L. C. O. Autonomia versus controle dos trabalhadores: a gestão do poder no hospital. Ciênc. saúde colet., Rio de Janeiro, v. 4, n. 2, p. 315-329. 1999.

Colegiados de gestão em serviços de saúde: um estudo empírico. Cad. Saúde Pública, Rio de Janeiro, v. 26, n. 3, p. 557-566. 2010.

CECILIO, L. C. O, MENDES, T. C. Propostas alternativas de gestão hospitalar e o protagonismo dos trabalhadores: por que as coisas nem sempre acontecem como os dirigentes desejam? Saúde e sociedade, São Paulo, v. 13, n. 2, p. 39-55. maio/ago. 2004. 
FERREIRA, V. L. As múltiplas faces da gestão: a prática gerencial nos serviços de saúde de Piraí. 2012. 100 f. Dissertação (Mestrado em Saúde Coletiva) - Universidade do Estado do Rio de Janeiro, Rio de Janeiro, 2012.

FRANCO, T. B. MERHY, E. E. O reconhecimento de uma produção subjetiva do cuidado. In:

Trabalho, produção do cuidado e subjetividade em saúde: textos reunidos. São Paulo: Hucitec. 2013. p. 151-171.

LITTIKE, D. Improvisando a gestão por meio da gestão do improviso: o processo de trabalho dos gestores de um hospital universitário Federal. 182f. Dissertação (Mestrado em Saúde Coletiva) - Universidade Federal do Espírito Santo, Vitória, 2012.

MERHY, E. E. Um dos grandes desafios para os gestores do SUS: apostar em novos modos de fabricar modelos de atenção. In: MERHY, E. E. et al. O trabalho em saúde: olhando e experienciando o SUS no cotidiano. São Paulo: Hucitec, 2007.

Saúde: a cartografia do trabalho vivo em ato. São Paulo: Hucitec, 2002.

O SUS e um dos seus dilemas: mudar a gestão e a lógica do processo de trabalho em saúde (um ensaio sobre a micropolítica do trabalho vivo). In: Teixeira, S. M. F. Saúde e democracia: a luta do Cebes. São Paulo: Lemos, 1997. 324 p.
PIMENTA, A. L. Saúde de amparo: a construção de espaços coletivos de gestão. 2006. Tese (Doutorado em Saúde Coletiva) - Universidade Estadual de Campinas, Campinas, 2006. Disponível em: < http://www.uff. $\mathrm{br} /$ saudecoletiva/professores/merhy/outros-02.pdf $>$. Acesso em: 07 out. 2013.

SOLLA, J. Dilemas e desafios da gestão municipal do SUS: avaliação da implantação do Sistema Municipal em Vitória da Conquista (Bahia), 1997-2008. São Paulo: Hucitec, 2010.

VANDERLEI, M. I. G. O Gerenciamento na Estratégia da Saúde da Família: o processo de trabalho dos gestores e dos gerentes municipais de saúde em municípios do Estado do Maranhão. Tese (Doutorado em Saúde Pública) - Escola de Enfermagem de Ribeirão Preto, Ribeirão Preto, 2005.

VANDERLEI, M. I. G.; ALMEIDA, M. C. P. A concepção e prática dos gestores e gerentes da estratégia de saúde da família. Ciênc. saúde colet., Rio de Janeiro, v. 12, n. 2, p. 443-453, abr. 2007. Disponível em: <http:// www.scielo.br/scielo.php?script=sci_arttext\&pid $=$ S141381232007000200021>. Acesso em: 27 jan. 2013

Recebido para publicação em abril de 2014

Versão final em dezembro de 2014

Conflito de interesses: inexistente

Suporte financeiro: não houve 